\title{
AC 2009-1027: THE DEVELOPMENT AND IMPLEMENTATION OF A NANOTECHNOLOGY MODULE INTO A LARGE, FRESHMAN ENGINEERING COURSE
}

\section{Vinod Lohani, Virginia Tech}

Vinod K Lohani is an associate professor in the Engineering Education Department and an adjunct faculty in the Civil and Environmental Engineering at Virginia Tech. He received a $\mathrm{PhD}$ in civil engineering from Virginia Tech in 1995. His research interests are in the areas of knowledge modeling, water and energy sustainability, engineering learning modules for freshmen, and international collaboration. He leads a major curriculum reform project, funded under the department-level reform program of the NSF, at Virginia Tech. A spiral curriculum approach is adopted to reformulate engineering curriculum in bioprocess engineering in this project. He co-authored an award winning paper with his PhD student (Jennifer Mullin) at the 2007 annual conference of ASEE. He received the College of Engineering Faculty Fellow award in 2008. His PhD co-advisee (Ricky Castles) won the third prize in a poster competition under the "Personalized Learning System" category at a Grand Challenges conference organized by the National Academy of Engineering at Duke University during March 02-03, 2009.

\section{Ganesh Balasubramanian, Virginia Tech}

Ganesh Balasubramanian is a PhD student at the Department of Engineering Science and Mechanics, Virginia Tech since Fall 2007. He received his undergraduate degree in Mechanical Engineering from Jadavpur University, India in May 2007. His doctoral research involves investigation of fluid flow and heat transfer processes across nanoscale interfaces using molecular simulations.

\section{Ishwar Puri, Virginia Tech}

Ishwar K. Puri is Professor and Department Head of Engineering Science and Mechanics (ESM) at Virginia Tech since 2004. He obtained his Ph.D. (1987), and M.S. (1984) degrees in Engineering Science (Applied Mechanics) from the University of California, San Diego after obtaining a B.Sc. (1982) in Mechanical Engineering from the University of Delhi. He was appointed as an Assistant Professor in the Mechanical Engineering Department at the University of Illinois at Chicago (UIC) in 1990, was promoted to the rank of Associate Professor with tenurein 1994, and to the rank of Professor in 1999. Puri is a Fellow of the American Society of Mechanical Engineers (ASME) and of the American Association for the Advancement of Science (AAAS).

\section{Scott Case, Virginia Tech}

Dr. Scott W. Case completed his Ph.D. studies at Virginia Tech in 1996 and began working as a post doctoral research associate. He became a Research Assistant Professor in 1997, an Assistant Professor in 1998, and an Associate Professor in 2003. He was named Associate Department Head in Engineering Science and Mechanics in 2005. He and his co-authors have been recognized for best paper awards by the American Society for Composites and the American Composites Manufacturers Association. His teaching and research accomplishments resulted in him receiving the College of Engineering's Outstanding New Professor Award for 2002, being named a College of Engineering Faculty Fellow in 2004, and receiving the College of Engineering Dean's Award for Research in 2007.

\section{Roop Mahajan, Virginia Tech}

Roop Mahajan serves as Director of the Institute for Critical Technology and Applied Science (ICTAS) at Virginia Tech where he also holds a joint appointment as tenured professor in the departments of Mechanical Engineering and Engineering Science Mechanics. His research interests include Bio-MEMS as sensors and actuators, Micro-fluidics, Thermal sciences, Artificial 
neural networks, Nanotechnology, Humanistic and Sustainable Engineering. He has published over 180 archival publications in these fields and has received national and international recognition world-wide recognition for his research. He is the recipient of many awards and honors including Bell Labs Fellow, ASME Heat Transfer Memorial Award, ASME Charles Richards Memorial Award and ASME Ralph Coats Gold Medal. He received the Ph.D. degree in mechanical engineering from Cornell University, Ithaca, NY in 1977 and B.S. and M.S. degrees in mechanical engineering from Punjab University, India. 


\title{
Development and Implementation of a Nanotechnology Module into a Large Freshman Engineering Course
}

\begin{abstract}
The development and implementation of a nanotechnology learning module into a freshman engineering course in Virginia Tech's large engineering program is discussed. This module, a part of a spiral theory based nanotechnology option that will be implemented in the curriculum of the Engineering Science Mechanics (ESM) department at Virginia Tech, was piloted with 180 freshmen in Spring '08. The pilot included a prior knowledge survey, a 40-minute in-class presentation on nanotechnology, a hands-on module involving analysis of nanoscale images, plotting of force functions at atomic scale using LABVIEW, and a post-module survey. Students' misconceptions, observed through the prior knowledge survey, were addressed in the in-class presentation and hands-on activities. In order to make the in-class presentation interactive, students' responses to a series of questions were collected in real time using Tablet PC and DyKnow technologies. Lessons learned in the Spring '08 pilot were incorporated to modify the module which was successfully implemented in the entire freshman engineering class of $~ 1500$ in Fall '08. Questions administered as part of a course exit survey indicated that about $15 \%$ students expressed interest in pursuing a nanotechnology option and about $65 \%$ students thought that nanotechnology was relevant in their intended field of engineering. Additionally, the survey revealed that a significant number of students were not clear about the role of gravitational forces at the nanoscale. Students also indicated interest in observing an actual nanotechnology experiment in a lab. Our experience indicates that LABVIEW provides a good environment to implement hands-on activities on nanotechnology concepts. However, caution should be exercised in developing LABVIEW based nanotechnology activities and more emphasis should be placed on nanotechnology concepts as compared to LABVIEW concepts. A series of nanotechnology learning experiences at the higher levels of learning are under development for creating the nanotechnology option within the ESM using the concept of spiral curriculum. This work is supported by the NSF's nanotechnology in undergraduate education (NUE) in engineering program.
\end{abstract}




\section{Introduction}

Virginia Tech offers one of the largest engineering programs in the US. A new Department of Engineering Education (EngE) was created within the College of Engineering (CoE) at Virginia Tech in May 2004 to improve engineering pedagogy within the $\mathrm{CoE}$ and to initiate engineering education research activities. The EngE offers a common one-year General Engineering (GE; also called freshman engineering) program for initial preparation of approximately 1500 incoming engineering freshmen. EngE faculty collaborate with faculty from other engineering departments and School of Education to develop engineering education research and curriculum development activities. A major ongoing NSF grant, funded (2004 - 2009) under the departmentlevel reform (DLR) program, has catalyzed the introduction of a spiral curriculum approach to reformulate the engineering curricula of bioprocess engineering and freshman engineering programs in the $\mathrm{CoE}^{1}$. The twentieth century psychologist, Jerome Bruner, proposed the concept of the spiral curriculum in his classic work The Process of Education ${ }^{2}$. Bruner advocates that a curriculum as it develops should revisit the basic ideas repeatedly, building upon them until the student has grasped the full formal apparatus that goes with them. In 2008, experiences in DLR project were extended to develop a nanotechnology option within the Engineering Science and Mechanics (ESM) department of CoE using the spiral curriculum approach. This effort is funded under the Nanotechnology in Undergraduate Education (NUE) in Engineering program of the NSF and is coordinated by nanotechnology and engineering education experts. In this paper, we discuss the proposed modules that are being/already implemented in support of the spiral theory based nanotechnology option within the ESM program. Additionally, we cover implementation details of a freshman module that is targeted at introducing basic nanotechnology concepts. This module, which sits at the bottom of the spiral framework, was successfully implemented in a freshman engineering course with $\sim 1500$ students in Fall 2008. Finally, we discuss our plans for implementing the remaining components of the nanotechnology spiral. 


\section{Nanotechnology Option within ESM Department}

The ESM department has 23 faculty members and 123 undergraduate students from sophomore to senior levels. The relatively small size of this department makes it an excellent venue for examining the effectiveness of the instructional options like the nanotechnology option proposed in this paper. Figure 1 shows a list of experiences/courses students will undergo as part of the proposed nanotechnology option within the ESM department. All engineering freshmen are introduced to basic fundamentals of nanotechnology to begin the spiral curriculum experiences. In addition to repeating basic nanotechnology concepts, students will be introduced to the societal and ethical aspects of this emerging technology at the next level of learning. During junior and senior levels, our proposed focus will be on developing activities that will focus on introductions to nanoscale material characterization and computational molecular mechanics. In the following sections, we discuss the implementation details of the freshman engineering module.

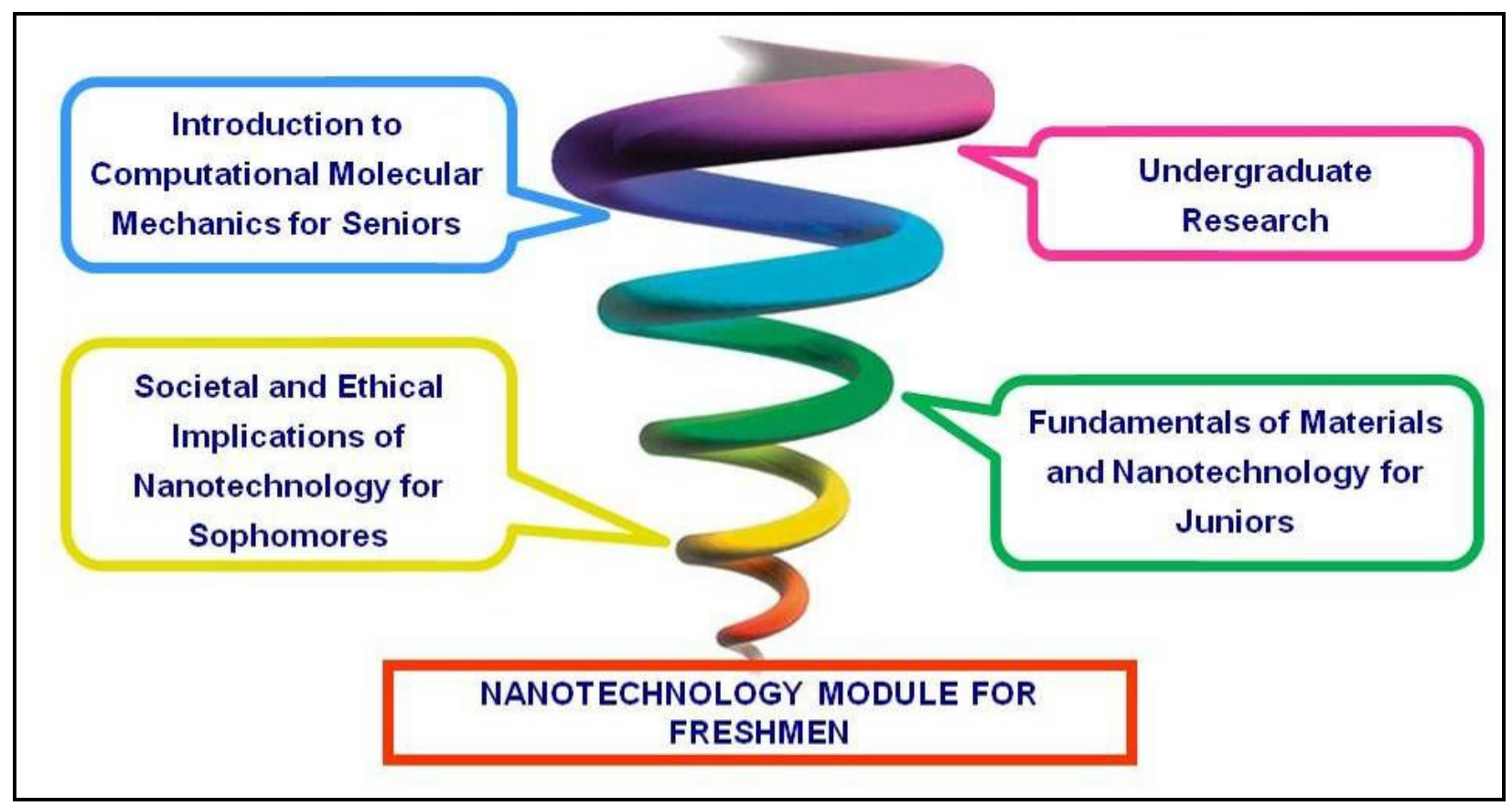

Figure 1: Spiral Curriculum - Nanotechnology Option 


\section{Freshman Engineering Nanotechnology Module}

All engineering freshmen are required to take a two credit Engineering Exploration (EngE1024) course during their first semester of enrollment in the GE program. This is the only common course all engineering undergraduates take within the CoE. The course primarily focuses on developing problem solving, critical thinking, and engineering design skills. The course delivery format includes a 50-min lecture followed by a 90-min hands-on workshop every week. Over the years, a number of hands-on activities have been implemented in this course, primarily due to the NSF/DLR project, to make it learner-friendly, contemporary and research-driven ${ }^{3,4}$. Some examples include: use of classroom response system (i.e., clickers) to obtain students' feedback ${ }^{5}$ , introduction to sustainability ${ }^{6,7}$, use of ethics skits to instruct engineering ethics ${ }^{8}$, introduction

of international activities ${ }^{9,9 a}$, use of electronic portfolio (e-portfolio) for instruction ${ }^{10,11}$, and use of mechatronics to introduce multi-disciplinary design to engineering freshmen ${ }^{12,13}$. In 2006-07 academic year, Tablet PC based instructions were introduced in this course ${ }^{14}$. A number of assessment (formative and summative) activities are being implemented in EngE1024 as part of the DLR project to evaluate the learning experiences of freshmen ${ }^{15,16,17,18}$. One of the learning objectives of the course is that after successful completion of the course the students will be able to demonstrate a basic awareness of contemporary global issues and emerging technologies, and their impact on engineering practice. As a contemporary emerging technology, the nanotechnology learning module was piloted in EngE1024 in Spring '08 and students' feedback was used to enhance the module which was implemented in the entire freshmen class in Fall ' 08. The following sections present the details.

\section{Development of Freshman Level Nanotechnology Learning Module}

Spring 2008 Pilot: Approximately 180 students enrolled in EngE1024 in Spring 2008. A nanotechnology learning module was piloted for the first time in the history of this course. This module included four components: (i) Prior Knowledge Survey, (ii) In-class Presentation, (iii) Hands-on Nanotechnology Activity, and (iv) Post Module Survey.

Prior Knowledge Survey: In order to assess students' prior knowledge related to nanotechnology, the investigators developed a short survey (see Appendix I) that included 10 questions. This 
survey was implemented 2 weeks before implementing nanotechnology instruction and hands-on activities. Figure 2 shows students' response to select survey questions. It was observed that about $73 \%$ students knew the definition of a nanometer. Further, about $40 \%$ students thought that gravitational force played a significant role at the nanoscale. Most of the freshmen were off by an order of magnitude when asked to identify the size of an atom. Also, most of the students thought that the most important application of nanotechnology was in the field of medical sciences. Only 5\% students had prior exposure to basic nanotechnology concepts and about $60 \%$ students expressed an interest in learning about nanotechnology. These results were used to design an in-class -presentation followed by a set of hands-on activities.
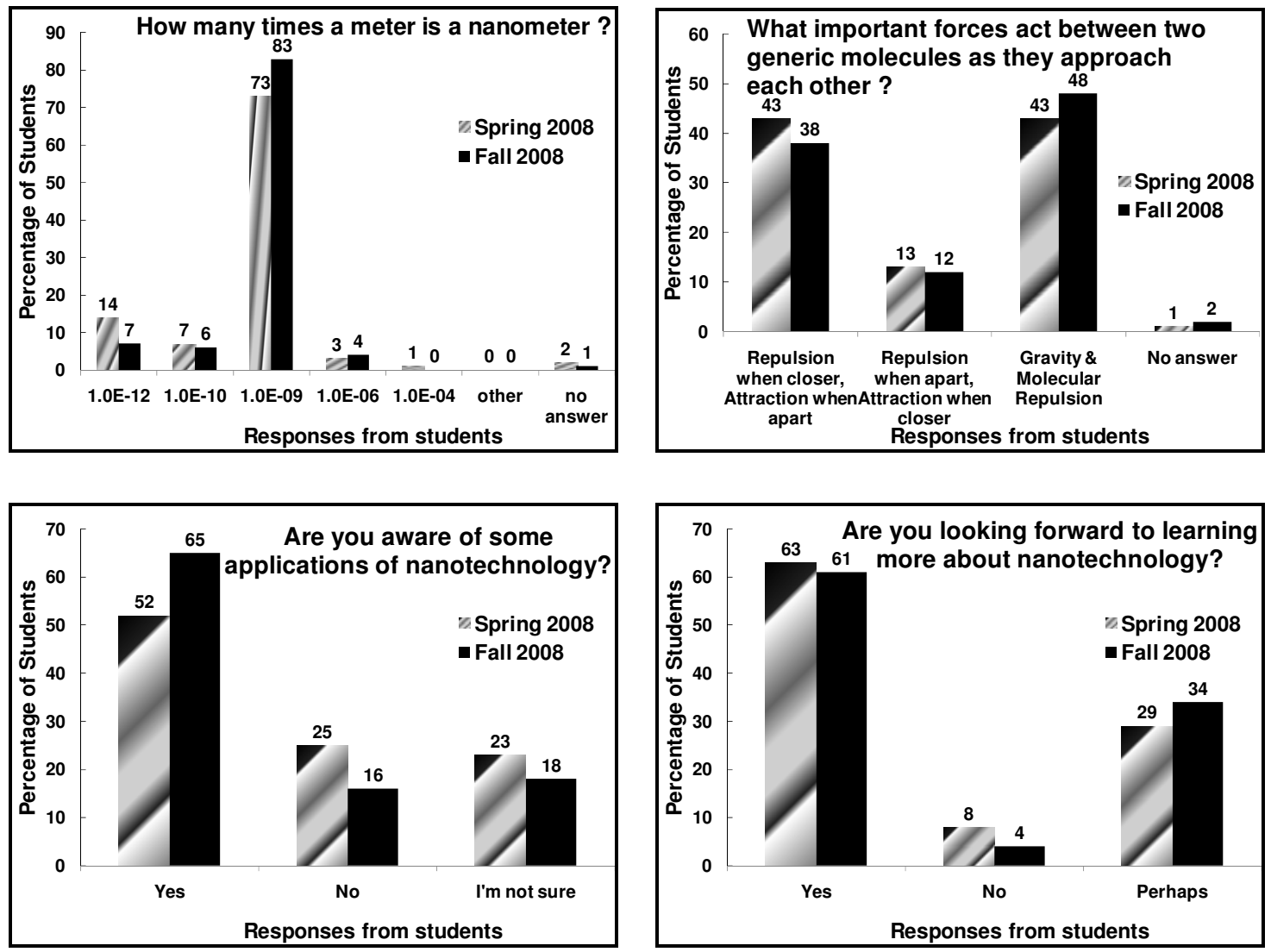

Figure 2: Prior Knowledge Response Summary (spring 08, n=99; fall 08, n=868)

In-class Presentation: A nanotechnology expert developed this presentation. Table 1 lists the key topics included in this presentation. Figure 3 shows some slides that are part of this presentation. 
Table 1: Key Topics Included in the 40-minute in-class presentation on nanotechnology

- Brief history of the subject

- Domain of nanotechnology amongst different length scales

- Interdisciplinary aspects

- Comparison of macroscale and molecular forces

- Molecular Mechanics

- Material behavior at the nanoscale

- Nanostructures in nature

- Applications: Everyday uses, Electronics, Nano-biotechnology etc.

- Ethical Issues
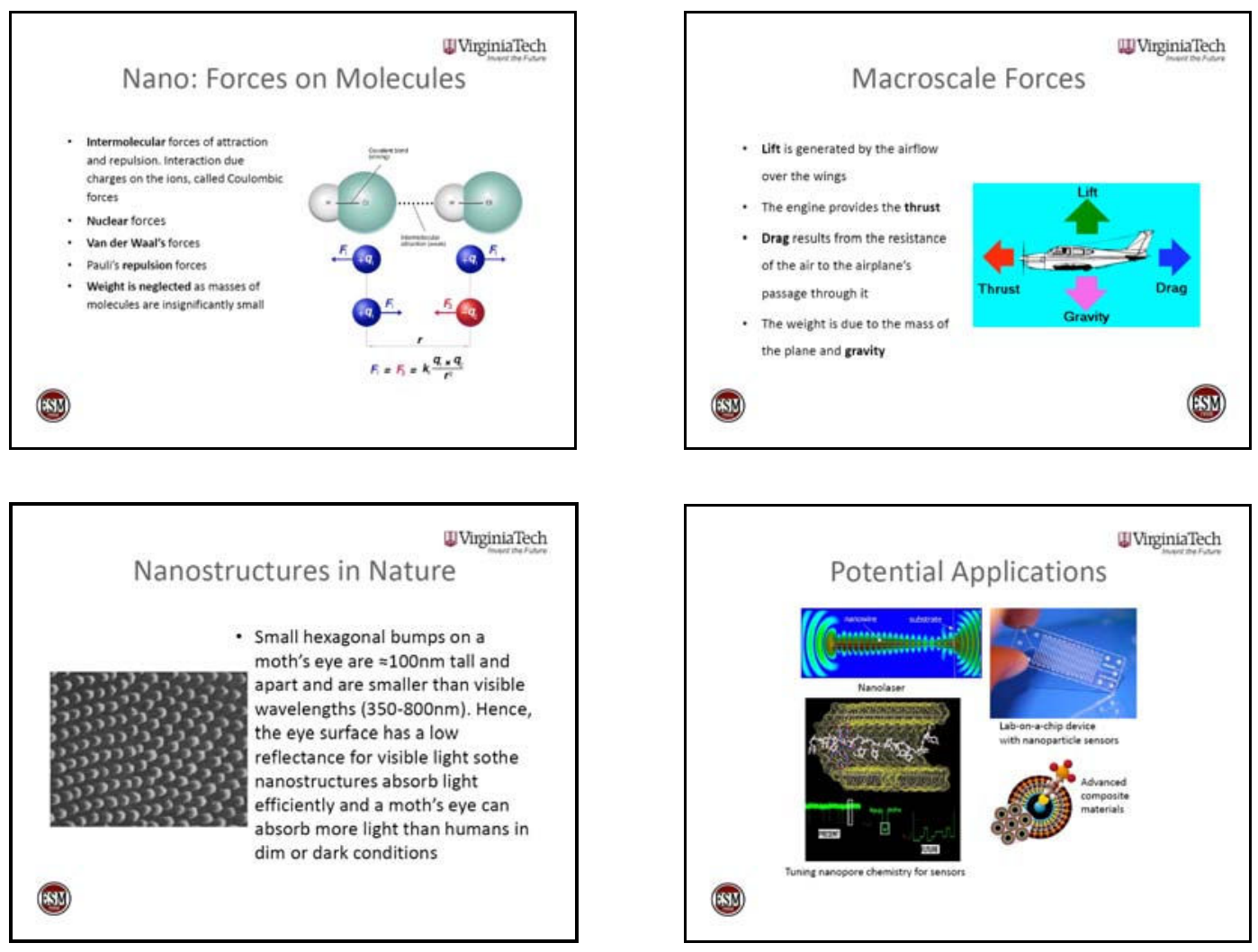

Figure 3: In-class Presentation Slides 
Engineering freshmen at this university are required to own a Tablet PC and lead author has developed/implemented TabletPC and DyKnow, a classroom interaction software, based instruction model for enhancing classroom instruction ${ }^{19}$. The authors took advantage of TabletPC/DyKnow technologies for enhancing classroom participation during the nanotechnology presentation. For example, in order to explain significance of various forces acting on a nanoscale, students were first asked to think about forces acting on a macro scale. They were assigned a short in-class exercise that involved sketching various forces acting on an airplane. Students' sketches were collected anonymously using TabletPC/DyKnow technologies (see Figure 4). As can be seen, one student understood the various forces acting on an airplane while the other student only thought of gravity. Student sketches, retrieved anonymously, were shown back to class to point out the deficiencies and encourage participation. Thereafter, the instructor's slide on forces at the macro scale (see Figure 4) was discussed.

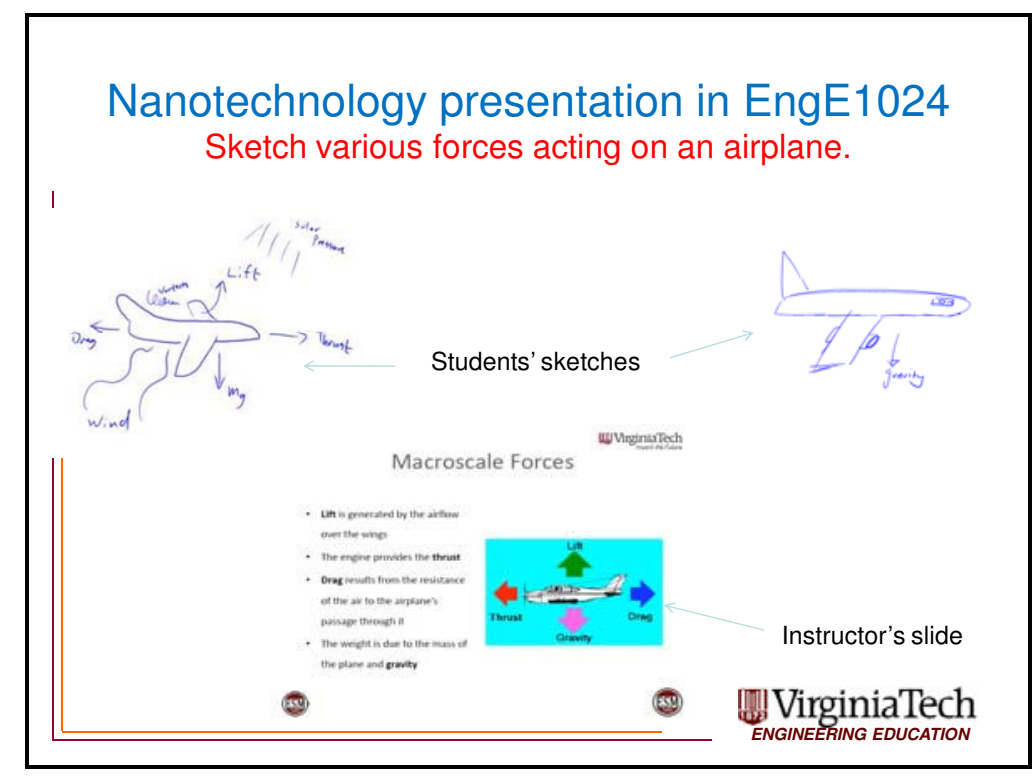

Figure 4: Example of feedback based teaching/learning

Hands-on Activity Workshop: Since students learn LABVIEW programming in EngE1024, it was decided to use the capability of this software to introduce nanotechnology concepts. Keeping in mind the information obtained from the prior knowledge survey, topics emphasized in the inclass presentation, concepts covered in EngE1024 prior to this module, and academic level of 
students, three nanotechnology exercises were developed in LABVIEW environment: (i) Measurement of sizes of carbon nanotubes, (ii) Introduction to and plotting of Lennard-Jones potential function, and (iii) Analysis of gravitational force between two atoms. Students were provided with nanotube images and they used the LABVIEW VISION toolkit to measure the size of carbon nanotubes (Figure 5(a)). In the second exercise, students were introduced to the Lennard-Jones potential function which is commonly used to model intermolecular forces of interaction in liquids. The students plotted the force function derived from the potential function and visually examined the nature of the interacting forces between two atoms (i.e., with increasing separation the attraction between atoms increases, while the closer two atoms come to each other repulsive forces become more and more stronger, see Figure 5(b)). Finally, students plotted the gravitational force as a function of separation distance between two atoms. This exercise further emphasized that gravitational forces are insignificant at the nanoscale due to the negligible molecular masses. Students were also assigned a couple of homework problems that further emphasized the nature of forces at atomic level.

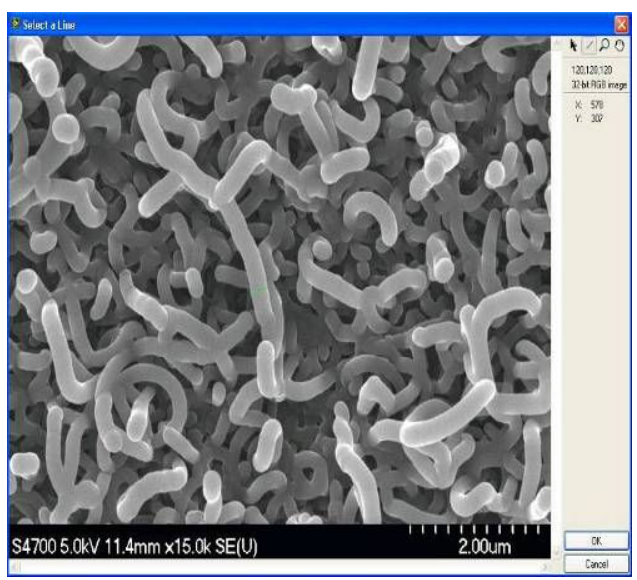

(a)

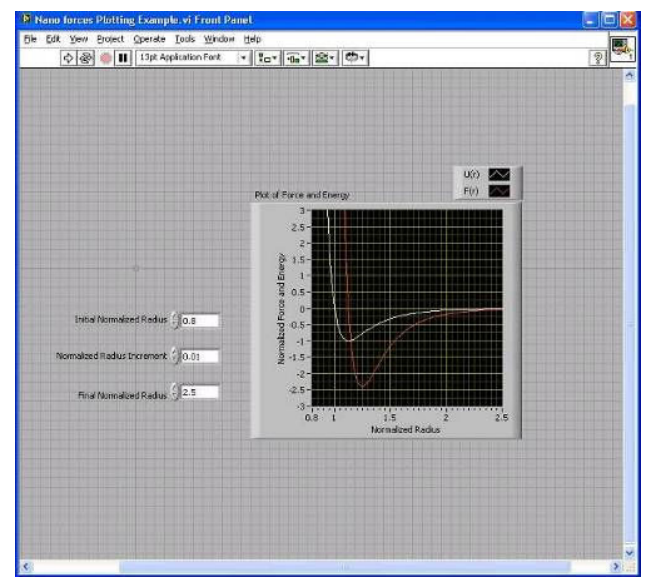

(b)

Figure 5: Hands-on activities in LABVIEW environment

Post-module Survey: As part of assessment activities in EngE1024, an exit survey has been developed and implemented since Fall ' $04^{18}$. Additional questions were added to this survey for students to complete at the end of Spring '08, including: 
1. Please recall (instructor's name) video presentation and workshop activities on nanotechnology this semester. These activities motivated me to pursue a nanotechnology minor/option.

\section{Strongly Agree/Agree/No Opinion/Disagree/Strongly Disagree}

2. Do you see the relevance of nanotechnology in your intended major of engineering? Yes/No/I have not decided a major yet

3. Please comment on your overall experiences of learning about nanotechnology and provide suggestions for future improvement. (Free response)

Students' responses to the questions 1 and 2 above are shown in Figures 6(a) and 6(b), respectively. Many students thought that a visit to a nanotechnology lab would be helpful in realizing the advances in nanotechnology. Also, students thought that the hands-on activities emphasized LABVIEW concepts more than the nanotechnology concepts. Regarding the in-class presentation, many students felt that too much material was covered in a single lecture and suggested an emphasis on nanotechnology applications in the class presentation. Finally, while a majority of the students thought that nanotechnology was relevant to their majors, about $26 \%$ showed interest in pursuing a minor/option in nanotechnology. Two key lessons learned in Spring '08 are: (i) Hands-on activities must emphasize nanotechnology concepts, and (ii) Students want to observe an actual nanotechnology experiment to develop a better understanding and appreciation for this emerging technology.

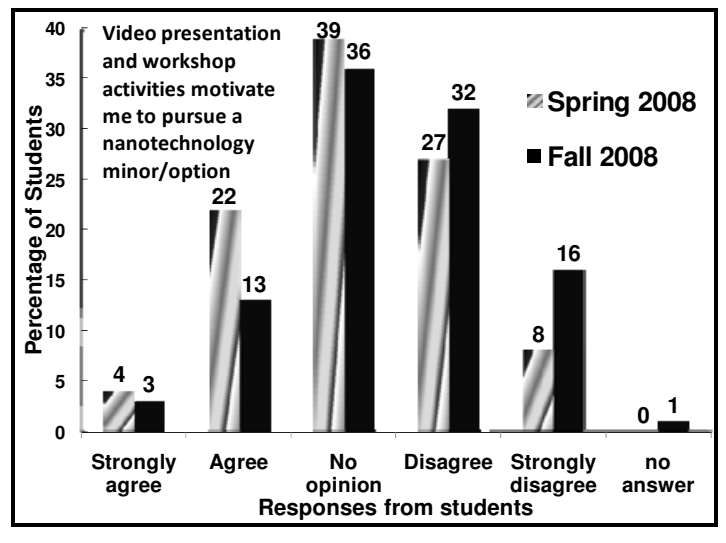

(a)

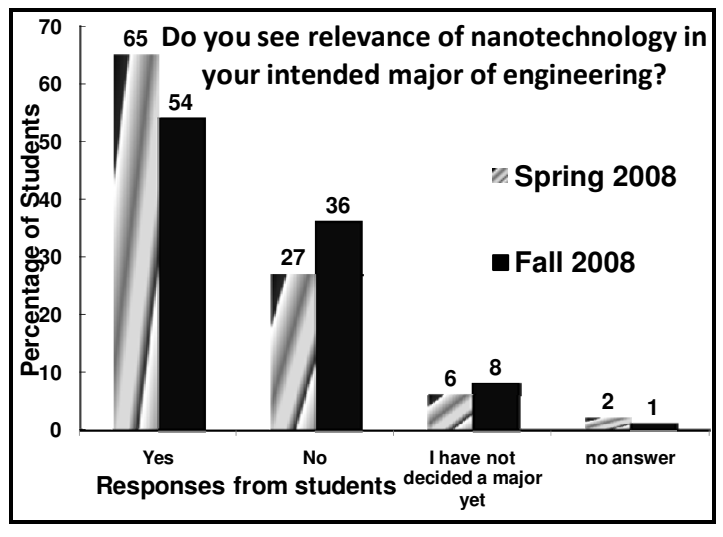

(b)

Figure 6: Students' responses to post-module survey (spring 08, n=49; fall 08, n=314) 
Fall 2008 Implementation: In Fall 2008, about 1500 freshmen enrolled in EngE1024. They were divided into eight large lecture sections and these lecture sections were further divided into 49 hands-on workshop sections. A video presentation of modified Spring '08 in-class presentation was recorded. Following activities were conducted to implement the nanotechnology learning module in the entire freshman engineering class: (i) Prior knowledge survey, (ii) Nanotechnology video assigned as a homework assignment, (iii) In-class Q/A session assisted by Tablet PC and DyKnow technologies, (iv) Hands-on activities, (v) Video presentation on a nanotechnology experiment, (vi) Homework assignments on nanotechnology concepts, and (vii) Post-module survey

Prior Knowledge Survey: The Spring '08 prior knowledge survey (see Appendix 1) was implemented on a voluntary basis and more than 50\% students responded (see Figure 2). Student responses indicated similar type of misconceptions as were observed in the Spring '08 pilot.

Nanotechnology video presentation: Students were assigned to review a nanotechnology video that was developed by a nanotechnology expert (i.e., third author). Students were given a week to review the video and were instructed to come prepared to class to ask questions on various concepts presented in this video.

In-class Q/A sessions: Three $\mathrm{PhD}$ students from the ESM department with nanotechnology research experience assisted EngE1024 instructors in facilitating the in-class Q/A sessions on nanotechnology concepts discussed in the video. Tablet PC and DyKnow technologies were used to obtain students' responses to the following three questions: (i) List the forces that dominate interaction between atoms at the nanoscale, (ii) List two engineering applications of nanotechnology discussed in this presentation. Can you also share example of an application that wasn't discussed in this presentation? and (iii) Suppose you are invited to your high school to give a short talk on your first year experiences at this university and you decided to say one thing about nanotechnology in this talk. What will you say?

Students were given about 2 minutes to respond. Their responses were retrieved anonymously using TabletPC/DyKnow technologies and graduate students reacted to students' feedback. Table 2 lists some responses from students. The issue of gravity not being a significant force at 
nanoscale was reiterated. In response to $2^{\text {nd }}$ question, students indicated applications related to bio-nanotechnology, space elevators and microchips. While most considered nanotechnology to be a huge area for scientific research and predicted development in medical sciences, some also raised critical opinions about ethical negative aspects of such powerful technologies, with imaginations drawn from "nano-babies" using DNA interactions to producing "nano-weapons" using novel high energy physics applications.

Table 2: Students' example responses during in-class Q/A session

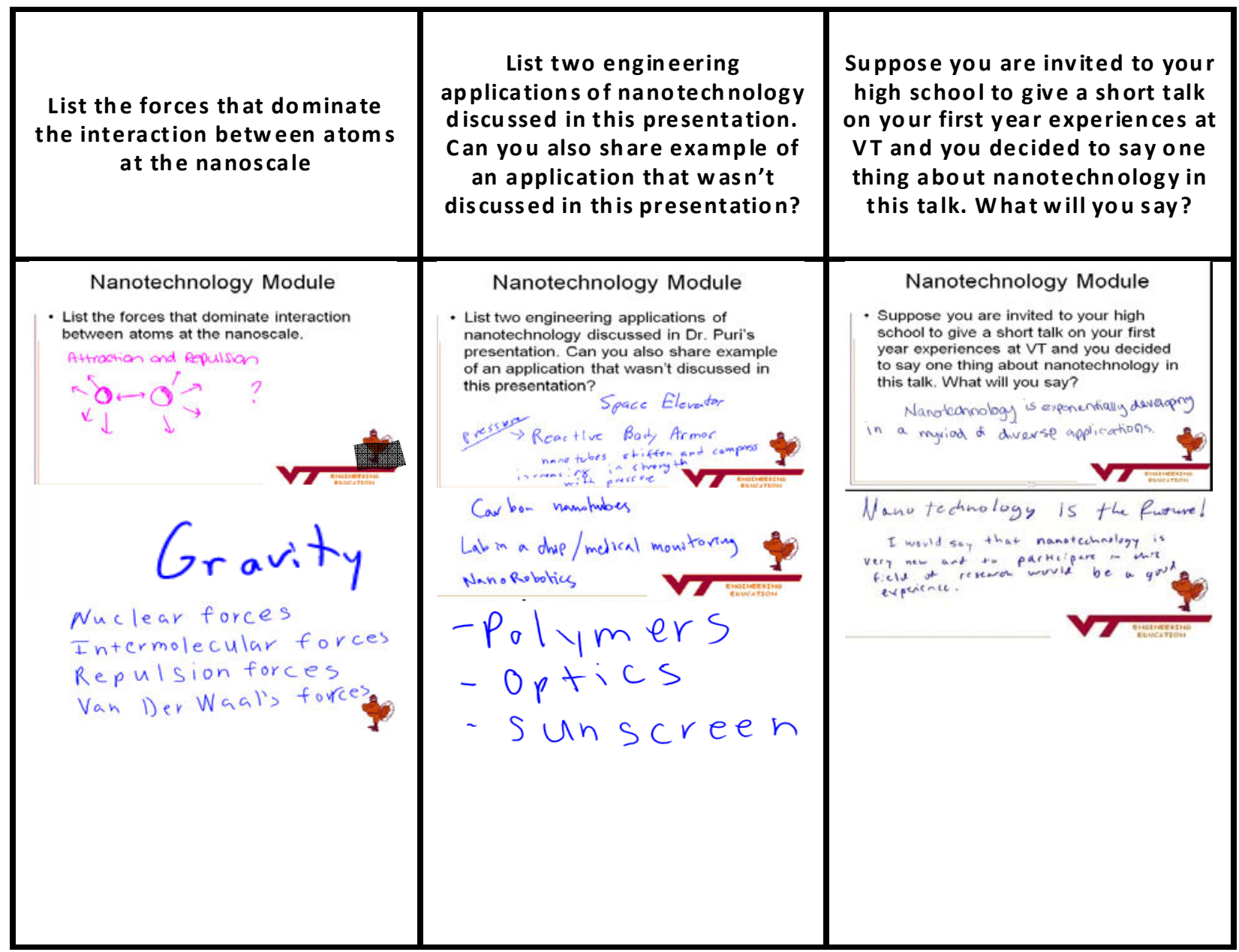

Hands-on Activity: The LABVIEW environment was used to repeat the hands-on activities that were done in spring '08 pilot. However, in order to provide a realistic picture of the size of nanotubes, a new exercise was developed that involved comparison of surface area to volume 
ratio between a nanotube and a PVC pipe. The objective was to demonstrate the role of surface area to volume ratio in determining the properties of many nanostructures. Students were asked to measure the diameter and length of a typical nanotube using Vision Toolkit in LABVIEW and to compute the surface area to volume ratio. They were also provided with the dimensions of a typical PVC pipe and computed surface area to volume ratio of the pipe and were asked to compare ratios of two tubes (i.e., a nanotube and a PVC pipe).

Nanotechnology experiment video: Students are assigned to watch a short video that demonstrated a nanotechnology experiment in a lab. In this 7-min video, students are introduced to a typical characterization experiment employed to study different nanostructures. The instrument used is a Scanning Electron Microscopy (SEM) that is equipped to capture high resolution magnified images of nanostructures for both physical and biological systems. An SEM expert, Steve McCartney, briefly explains the techniques involved in the preparation of the sample and salient features and capabilities of the instrument. Images of a human hair and carbon nanotubes are captured and different structure characteristics are explained.

Post-module survey: Questions added to the EngE1024 exit survey in the Spring '08 pilot were asked of all freshmen at the end of the Fall '08 semester. About 314 students responded. Figures 6(a) and (b) show Fall '08 responses. Students felt that the video presentation was too long and dealt with a variety of concepts. They also preferred more discussion on real life applications rather than explanation of concepts, which they thought was difficult to understand, especially those who had no plans on pursuing nanotechnology as part of their curriculum. With regards to hands-on activities, most students still thought that LABVIEW skills were emphasized and indicated preference for a real-time demonstration of nanoscale activity

\section{Summary and Future Work}

This paper demonstrates collaborative work between two engineering departments and an interdisciplinary university-level institute targeted at creating a nanotechnology option within the ESM covering current and emerging topics at Virginia Tech. The nanotechnology option is based on the well established spiral theory and includes/will include topics with increasing level of complexity. We discussed our experiences of developing a module at freshman level in this 
paper. Lessons learned and our findings include the following: (i) Video presentation covering nanotechnology concepts should be limited to 20 minutes, (ii) LABVIEW presents a good environment to develop hands-on activities on nanotechnology concepts. However, these activities should emphasize nanotechnology concepts more than the LABVIEW concepts, (iii) About $15 \%$ students showed interest in pursuing nanotechnology option, and (iv) Students showed interest in observing a real nanotechnology experiment. Therefore, if possible, we recommend to use possible hands-on activities in a nanotechnology learning module for freshmen. Size of our program prevents us from doing so. In addition to the surveys, we plan to do focus group sessions in future to better understand students' responses. We have proposed to introduce "societal and ethical implications of nanotechnology" at the next level of learning. During junior and senior levels, our proposed focus will be on developing activities that will focus on introductions to nanoscale material characterization and computational molecular mechanics. The authors will be happy to share various learning modules once these are successfully developed and implemented.

\section{Acknowledgement}

The authors acknowledge the support of the National Science Foundation (Grant 0741364). We also thank all EngE1024 instructors and graduate teaching assistants who helped us in implementing the nanotechnology module in the entire freshman class.

\section{Bibliography}

[1] Lohani, V.K., Sanders, M., Wildman, T., Connor, J., Mallikarjunan, K., Dillaha, T., Muffo, J., Knott, T.W., Lo, J., Loganathan, G.V., Adel, G., Wolfe, M.L., Goff, R., Gregg, M., Chang, M., Agblevor, F., Vaughan, D., Cundiff, J., Fox, E., Griffin, H., and Magliaro, S., 2005. "From BEEVT to DLR: NSF Supported Engineering Education Projects at Virginia Tech," Proc. 2005 Annual Meeting and Conference of the American Society for Engineering Education, Portland, Oregon, June 12-15, 2005. 
[2] Bruner, J. (1960). The Process of Education. Cambridge, MA: Harvard University Press.

[3] Lo, J.L., Lohani, V.K. \& Griffin, Jr., O.H. (2006). Full Implementation of a New Format for Freshmen Engineering Course. Proceedings of the 2006 ASEE Annual Conference and Exposition, Chicago, IL, June 18-21, 2006, 15 pages.

[4] Lohani, V. K., Wildman, T., Connor, J., Mallikarjunan, K., Wolfe, M. L., Muffo, J., Knott, T.W., Lo, J., Loganathan, G.V., Goff, R., Gregg, M., Chang, M., Cundiff, J., Adel, G., Agblevor, F., Vaughan, D., Fox,' E., Griffin, O.H., Mostaghimi, S., 2005. "Work in Progress: Spiral Curriculum Approach to Reformulate Engineering Curriculum," Proceedings of the Annual Frontiers in Education Conference, Indianapolis, IN, October 18-21, 2005.

[5] Lohani, V. K., \& Lo, J.L. (2006). Clicker-Based Assessment in an Engineering Course. Virginia Tech Center for Excellence in Undergraduate Teaching Year-End Poster Session, Blacksburg, Virginia, May 4, 2006.

[6] Mullin, J.S., Lohani, V.K., Lo, J.L., and Griffin, O.H. (2006). Sustainable Development Design Projects for Engineering Freshmen. Proceedings of the 2006 ASEE Annual Conference and Exposition, Chicago, IL, June 18-21, 2006, 11 pages, USA.

[7] Mullin, J., Jinsoo, K., Lohani, V. K., and Lo, J. (2007). Sustainable Energy Design Projects for Engineering Freshman. Proceedings of the 2007 ASEE Annual Conference and Exposition, Honolulu, HI, June 24-27, 2007.

[8] Mullin, J.S., Lohani, V.K., \& Lo, J.L. (2006). WIP: Introduction to Engineering Ethics through Student Skits in the Freshman Engineering Program at Virginia Tech. Proceedings of the $36^{\text {th }}$ ASEE/IEEE Frontiers in Education Conference, San Diego, CA, October 28- November 1, 2006. pp S2H-21 - S2H-22.

[9] Jayaraman, P., Lohani, V. K., Bradley, G., Griffin, H., and Dooley, J., 2008. "Enhancement of International Activities in a Large Engineering Curriculum," Proc. 2008 ASEE Annual Conference, June 22-25, 2008, Pittsburgh.

[9a ] Lohani, V., Mullin, J., Lo, J., \& Griffin, H. (2006). Implementation of international activities in a freshman engineering course. Proceedings 2006 ASEE Global Colloquium on Engineering Education, Rio de Janeiro, Brazil, October 9-12, 2006, 13 pages.

[10] Knott, T. W., Lohani, V. K., Griffin, O. H., Loganathan, G. V., Adel, G., \& Wildman, T. (2004). Bridges for Engineering Education: Exploring e-Portfolios in Engineering Education at Virginia Tech. Proceedings of the 2004 ASEE Annual Conference and Exposition, Salt Lake City, Utah, June 20-23, 2004, 15 pages.

[11] Knott, M., Lohani, V.K., Griffin, O.H., Loganathan, G.V., Adel, G., Paretti, M., et al. (2005). Using eportfolios in a large engineering program. Proceedings of the 2005 ASEE Annual Conference and Exposition, Portland, Oregon, June 12-15, 2005, 16 pages.

[12] Lohani, V.K., Kachroo, P., Chandrachood, S., Zephirin, T. Loganathan, G.V., \& Lo, J.L. (2006). Mechatronics Experiment in a Freshman Year Course. Proceedings of the 2006 International Conference on Engineering Education (iCEE06), Puerto Rico, July 23-28, 2006, 5 pages.

[13] Castles, R., Zephirin, T., Lohani, V. K., and Kachroo, P., Analysis of Freshman Students' Experiences in a Mechatronics Hands-on Workshop in a Large Engineering Program, IEEE Transactions on Education (in review). 
[14] Lohani, V., Castles, R., Lo, J., \& Griffin, H. (2007). Tablet PC Applications in a Large Engineering Program. Proceedings of the 2007 ASEE Annual Conference and Exposition, Honolulu, HI, June 24-27, 2007, 13 pages.

[15] Muffo, J., Lohani, V.K., Mullin, J., Backert, R., \& Griffin, O.H. (2005). From Engineering Fundamentals to Engineering Education - What's in a Name. Invited paper, Proceedings of the International Conference on Engineering Education \& Research (iCEER05), Tainan, Taiwan, March 1-5, 2005.

[16] Robson, V., Muffo, J., \& Lohani, V. (2006). The Little engineer that could: Background, attitudinal, and academic predictors of student success. Poster presented at Association for Institutional Research Annual Forum, Chicago, IL.

[17] Robson, V., Lohani, V. K. \& Bateman, T., (2007). Foundational Predictors of Success in the Collegiate Engineering Program. Proceedings of the 2007 ASEE Annual Conference and Exposition, Hawaii, June 2427, 2007, 11 pages.

[18] Robson, V., Lohani, V. K., and Muffo, J., 2008. "Assessment in Engineering Education, Book Chapter in Assessment in the Disciplines," Vol. 3, Assessment in Engineering Programs: Evolving Best Practices, Editor: William E. Kelly, pp. 173-192, Association for Institutional Research, Tallahassee, FL.

[19] Lohani, V. K., Castles, R., Johri, A., Spangler, D., and Kibler, D., 2008. "Analysis of Tablet PC Based Learning Experiences in Freshman to Junior Level Engineering Courses," Proc. 2008 ASEE Annual Conference, June 22-25, 2008, Pittsburgh. 


\section{Appendix I}

List of questions with the multiple answer choices posted for students in the Prior Knowledge Survey

1. Do you know what nanotechnology is? Yes/No/Not Sure

2. What is a nanometer? $10^{-12} \mathrm{~m} / 10^{-10} \mathrm{~m} / 10^{-9} \mathrm{~m} / 10^{-6} \mathrm{~m} / 10^{-4} \mathrm{~m} /$ Other

3. What is the typical size of an atom? $10^{-12} \mathrm{~m} / 10^{-11} \mathrm{~m} / 10^{-10} \mathrm{~m} / 10^{-9} \mathrm{~m} / 10^{-8} \mathrm{~m} / 10^{-6} \mathrm{~m} /$ Other

4. What influences an apple as it falls from a tree?

The fluid drag on it from the surrounding air/Gravity/Gravity and fluid drag from the surrounding air/The earth's electric field/The earth's electric field and gravity and fluid drag/Sunspots/Sunspots and the earth's electric field and gravity and fluid drag

5. What important forces act on two different generic molecules as they approach each other?

Attraction between molecules when they are far apart and repulsion between them as they come closer/Repulsion between molecules when they are far apart and attraction as they come closer/The gravitational force and the molecular repulsion between molecules

6. For how long do you think have scientists been formally working on nanotechnology? Last decade/last twenty years/last fifty years/last century/last millennium

7. Are you aware of some applications of nanotechnology? Yes/No/Not Sure

8. Have you had formal instruction about nanotechnology in high school or college? Yes/No/Not Sure

9. Have you ever visited a research laboratory or worked in it? Yes/No/Not Sure

10. Are you looking forward to learning more about nanotechnology? Yes/No/Not Sure 